\title{
Tumour Lysis Syndrome: The Forgotten Oncologic Emergency
}

\author{
*Uma Hariharan and Vinodh Natarajan \\ Anesthesia \& Intensive Care, Dr Ram Manohar Lohia Hospital \& PGIMER, India
}

Submission: October 27, 2017; Published: November 10, 2017

"Correspondence Address: Uma Hariharan, MBBS, DNB, PGDHM, Fellowship Oncoanaesthesia \& Advanced Regional anaesthesia Assistant Professor Anesthesiology and Intensive Care, Dr Ram Manohar Lohia Hospital \& Post Graduate Institute of Medical Education and Research (Dr RMLH \& PGIMER, CHS), Central Health Services, New Delhi, India, Email: uma1708@gmail.com

Abbreviations: TLS: Tumour Lysis Syndrome; ICU: Intensive Care Unit; LTLS: Laboratory Tumour Lysis Syndrome CTLS: Clinical Tumour Lysis Syndrome

\section{Editorial}

With the increasing incidence of various cancers worldwide, there is a major surge in the administration of chemo-radiotherapy to these patients at different points of anti-cancer therapy. There are numerous side-effects and complications of cancer chemotherapy, which can alter the overall outcome. One of the rare, but fatal complications is TLS. Tumour lysis syndrome [1] is a multi-system disorder, caused by massive and abrupt release of cellular components into the blood after the rapid lysis of malignant cells which are particularly rich in uric acid, phosphate and potassium. Potassium in excess leads to severe skeletal muscle dysfunction, ventricular arrhythmias and cardiac arrest. Uric acid is the final by-product of purine metabolism in humans. Uric acid can crystallize and obstruct the flow in renal tubules, leading to acute kidney injury. Excess phosphate in blood combines with calcium and forms calcium phosphate which gets deposited in kidneys mediating acute kidney damage. And as a result, calcium levels in blood may fall and lead to hypocalcaemia sequalae. Calcium phosphate also facilitates the deposit of uric acid crystals in kidney [2]

There is no universally accepted system for classification and grading of TLS. The most recent and preferred one is Cairo and Bishop classification system 2004 [3], based on defining laboratory or clinical tumour lysis syndrome (LTLS or CTLS). This system distinguishes between the patients who do not require therapeutic intervention versus the patients requiring intensive care unit (ICU) admission. Under this system, LTLS is considered to be present if levels of two or more serum values of uric acid, potassium, phosphorus or calcium are more than or less than normal at presentation or if they change by $25 \%$ within 3 days before or 7 days after the initiation of chemotherapy. CTLS requires the presence of LTLS in addition to one or more of the following significant clinical complications: renal insufficiency, cardiac arrhythmias, seizures and sudden death [4].
Though there have been several recent advances in the management of this oncologic emergency. morbidity and mortality from TLS still remains high. There should be screening of high-risk patients prone to develop TLS. Institution of chemotherapy in these patients should be done preferably in an ICU set up. Vigilant monitoring of vital parameters, including invasive monitors, arterial blood gases and electrocardiogram may be required in patients with concurrent renal or cardio-respiratory comorbidities. All blood chemistries, including serum electrolytes (Sodium, Potassium, Phosphorous and Calcium), renal function tests, blood counts, coagulation profile, calcium-phosphate product, reticulocyte count and liver function tests must be carried out before and after administration of chemotherapeutic agents. Maintenance of adequate hydration and prevention of end-organ damage is the corner stone of management. Some patients may require renal replacement therapy [5]. Early recognition of complications and prompt ICU admission is of paramount importance for successful outcome in oncoemergencies. Close co-ordination between the oncologist, intensivist, nutritionist and nephrologist plays a pivotal role in the recognition and management of TLS. Future cancer research must focus on multi-center randomized controlled trials on protocol-based, preventive and treatment strategies for this rare, but serious syndrome.

\section{References}

1. Aibek E Mirrakhimov, Prakruthi Voore, Maliha Khan, Alaa M Ali (2015) Tumor lysis syndrome: A clinical review. World J Crit Care Med 4(2): 130-138.

2. Rampello E, Fricia T, Malaquaranera M (2006) The management of tumor lysis syndrome. Nat Clin Pract Oncol 3: 438-447.

3. Cairo MS, Bishop M (2004) Tumour lysis syndrome: new therapeutic strategies and classification. Br J Haematol 127(1): 3-11. 


\section{Cancer Therapy \& Oncology International Journal}

4. Thiery G, Darmon M, Azoulay E (2007) Deciding intensive care unitadmission for critically ill cancer patients. Indian J Crit Care Med 11: 12-18.

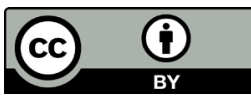

This work is licensed under Creative Commons Attribution 4.0 License DOI: $10.19080 /$ CTOIJ.2017.07.555723
5. Lamaire N, Vanholder R, Biesen WV, Benoit D (2016) Acute kidney injury in critically-ill cancer patients: an update. Critical Care 20: 209.

Your next submission with Juniper Publishers will reach you the below assets

- Quality Editorial service

- Swift Peer Review

- Reprints availability

- E-prints Service

- Manuscript Podcast for convenient understanding

- Global attainment for your research

- Manuscript accessibility in different formats ( Pdf, E-pub, Full Text, Audio)

- Unceasing customer service

Track the below URL for one-step submission https://juniperpublishers.com/online-submission.php 